\title{
Tercera guerra verde: Antecedentes, características y proceso de paz del periodo de violencia del occidente de Boyacá (1986-1990)*
}

\section{Third Green War: Background, characteristics, and peace process of the violence period in western Boyacá (1986-1990)}

\author{
María Camila Bohórquez Malagón** \\ Juan Diego Olaya Wilches*** \\ Santiago Mosquera Zambrano ${ }^{* * * *}$
}

\section{Resumen}

El presente artículo busca indagar acerca de los antecedentes, características, dinámicas y consecuente proceso de paz, del periodo conocido como tercera guerra verde en el occidente del departamento de Boyacá, entre los años 1986 y 1990. De modo que el objetivo de la presente investigación consiste en enunciar y analizar las

Artículo de Revisión.

** María Camila Bohórquez Malagón. Tesista del programa de Ciencia Política, Universidad de San Buenaventura, sede Bogotá. Integrante del semillero de investigación Ciudades y Territorios Incluyentes de la Facultad de Ciencias Jurídicas y Políticas.

*** Juan Diego Olaya Wilches. Tesista del programa de Ciencia Política, Universidad de San Buenaventura, sede Bogotá. Integrante del semillero de investigación Ciudades y Territorios Incluyentes de la Facultad de Ciencias Jurídicas y Políticas.

$* * *$ Santiago Mosquera Zambrano. Politólogo, Universidad de San Buenaventura, sede Bogotá. Integrante del semillero de investigación Conflicto, Historia y Acción Humanitaria de la Facultad de Ciencias Jurídicas y Políticas. 
circunstancias sociales, históricas y económicas que se presentaron en estos municipios del occidente del departamento de Boyacá para que hubiera una fuerte intensificación de la violencia en este periodo, lo cual conllevó, posteriormente, a que se firmaran acuerdos de paz. Además, se analizarán las consecuencias del acuerdo y proceso de paz en esta región de Colombia, en torno a la resolución del conflicto social, económico y político que allí se gestó en relación con el negocio de las esmeraldas.

\section{Palabras clave}

Guerra verde, occidente de Boyacá, bando Coscuez, bando Borbur, proceso de paz

\section{Abstract}

This article seeks to inquire about the antecedents, characteristics, dynamics and consequent peace process of the period known as the third green war in the western department of Boyacá, between 1986 and 1990. Thus, the objective of this research It consists of stating and analyzing the social, historical and economic circumstances that arose in these western municipalities of the department of Boyacá so that there was a strong intensification of violence in this period, which subsequently led to the signing of peace agreements. In addition, the consequences of the agreement and peace process in this region of Colombia will be analyzed, regarding the resolution of the social, economic, and political conflict that arose there in relation to the emerald business.

\section{Key Words}

Green war, western Boyacá, Coscuez side, Borbur side, peace process 


\section{Introducción}

La violencia ha tenido diferentes presentaciones e intensidades en las diferentes regiones del país, esto a causa de las características geográficas y formación institucional que cada una ha tenido a nivel histórico, lo cual conlleva a que el conflicto se desarrolle de manera localy no generalizada.

En el caso concreto del occidente de Boyacál, el conflicto ha estado enmarcado en unas lógicas diferentes a las de otros territorios del país, donde el narcotráfico y la presencia de grupos armados ilegales son la principal fuente de violencia. La economía de esta zona del país gira en torno al mercado de esmeraldas, el cual, históricamente, se ha constituido como uno de los principales ejes de violencia en la zona. Sumado a ello está la disputa por el control territorial de las minas de esmeraldas, que se dio en los años setenta y ochenta del siglo xx, cuando se constituyó el Bando de Coscuéz y el Bando de Borbur (Gutiérrez y Barón, 2008). Como resultado del análisis de estos dos factores causantes de violencia, se evidencia que entre $1986^{2}$ hasta $1990^{3}$ hay un período de guerra y paz, donde la violencia esmeraldera tiene su mayor incidencia.

Esta intensificación se puede explicar gracias a la participación del Estado y la empresa privada en la zona, de la cual hacían parte varios esmeralderos. Esto generó que el panorama social de esta zona cambiara de manera radical y que la violencia se intensificara significativamente. Por lo tanto, fue necesario el establecimiento de un

1 Principalmente en los municipios de Muzo, Pauna, San Pablo de Borbur y Otanche

2 En 1986 se agudiza el conflicto en la zona como resultado de la resolución 337 de 1977, con la cual el gobierno comienza a privatizar las minas, lo cual dejó como resultado la división interna de los jefes esmeralderos, quienes por un lado lograron constituir una empresa para explorar las minas de manera legal, pero por otro lado estuvieron quienes se opusieron a la presencia del Estado y prefirieron continuar con técnicas tradicionales como el guaqueo, que luego se convertirían en técnicas ilegales de exploración.

3 En 1990 se crea el Consejo de Paz, encargado de velar por el cumplimiento del acuerdo de paz entre esmeralderos del occidente de Boyacá, en 1989. 
proceso de paz que condujera a la región a la solución del conflicto generado por la explotación esmeraldera, y presente allí por décadas.

\section{Antecedentes generales de la Tercera Guerra Verde del occidente de Boyacá}

Para hablar de la Tercera Guerra Verde (1986-1990) se deben tener en cuenta diversos antecedentes que marcan las relaciones sociales del occidente de Boyacá, y que en últimas son una de las causas principales del recrudecimiento de la violencia en dicho período. Para ello es primordial entender cómo se configuró el poblamiento de estas zonas y la configuración de este aspecto en un escenario estatal bastante precario, donde el Estado no funcionó como un agente clave en la constitución de un contrato social robusto que permitiera la participación de los diversos actores que surgieron en medio de las disputas por el control de las minas de esmeraldas del occidente de Boyacá.

La violencia de los treinta ${ }^{4}$ trajo consigo un flujo migratorio de muchos campesinos y campesinas de departamentos como Cundinamarca, Tolima y Santander, quienes buscaban nuevas oportunidades en los territorios que poco a poco iban colonizando. Steiner (2005) menciona que el occidente de Boyacá fue un rincón seguro para los campesinos pobres de Cundinamarca y Santander, que fueron forzados a dejar sus tierras durante La Violencia ${ }^{5}$. Sumado a ello, dicha zona era un espacio territorial alejado de los centros políticos, lo cual funcionó para que se generaran órdenes subalternos que no contaban con la presencia del Estado y garantizaron el surgimiento de liderazgos regionales, lo que años más tarde se reflejaría

4 Categoría que se puede ampliar revisando los dos tomos de 'La Violencia en Colombia' (1962), escrito por Monseñor Germán Guzmán, Eduardo Umaña Luna y Orlando Fals Borda.

5 La Violencia, con mayúscula y como período, fue "una serie de procesos provinciales y locales sucedidos en un período que abarca de 1946 a 1964, donde descargó su mayor fuerza destructiva entre 1948 y 1953" (Palacios y Safford, 2012). 
en fuertes patronazgos ${ }^{6}$ que regularían la vida social, económica y política de la región.

Sin embargo, el proceso de organización en torno a la explotación de este mineral fue bastante desorganizado. Las relaciones sociales y económicas de la población habían comenzado a girar en torno a la esmeralda, lo cual significó el surgimiento de diferentes instituciones informales en el marco de la ilegalidad, pero motivadas por la falta de presencia efectiva del Estado; una presencia que integrara todas las subjetividades presentes en el territorio y lograra establecer vínculos sociales y económicos con los jefes esmeralderos y los mineros.

Para finales de la década de los cincuenta las minas de esmeralda no eran para el Estado una fuente de ingresos, más bien eran un dolor de cabeza (Steiner, 2005), ya que el $95 \%$ del mercado mundial de esmeraldas dependía del mercado negro colombiano (Gutiérrez \& Barón, 2008). Frente a este panorama, el gobierno de Alberto Lleras Camargo reaccionó con la expedición de la ley 145 de 1959, la cual reservó todos los derechos de la explotación de minas a los esquemas dispuestos por el Estado, esto como una ofensiva ante las instituciones informales que se habían creado en torno a la obtención del mineral mediante técnicas clandestinas, como el guaqueo. Sin embargo, el efecto de esta ofensiva del Estado fue contraproducente, ya que las técnicas ilegales de minería se intensificaron en toda la zona, mientras que el Banco de la República ${ }^{7}$ poco a poco iba perdiendo legitimidad.

6 Los patrones eran los líderes indiscutibles de la región, ganaron poder y autoridad mediante el uso de la fuerza, y con ayuda de ejércitos propios, con el fin de controlar las minas esmeralderas. Asimismo, el patrón actuaban como agente representativo de una colectividad de esmeralderos y, en ocasiones, llega a ser la voz de toda una zona ante el Estado.

7 El Banco de la República era la entidad estatal encargada de regular el negocio de las esmeraldas en la zona hasta llegada la década de 1970. 
La primera década de los sesenta fue clave en la configuración de un régimen subalterno en el occidente de Boyacá; dicho régimen permitió que los jefes esmeralderos tuvieran una mayor participación en la vida política, social, económica y cultural de las personas, lo cual generó un alto grado de confianza y lealtad por parte de los mineros y habitantes de los municipios hacia un patrón. Muchas son las estrategias que usaron los jefes esmeralderos para hacerse con la confianza de los mineros, entre ellas se puede evidenciar el uso de la religión (en este caso catolicismo ${ }^{8}$ ) como herramienta de control y legitimación; el patrocinio de eventos socioculturales de índole popular ${ }^{9}$, y el uso de un discurso basado en el surgimiento desde lo más bajo. Sobre este último punto, el estudio antropológico de María Victoria Uribe funciona para entender estas dinámicas:

En la zona esmeraldífera todo gira alrededor de estos individuos que pertenecen a la comunidad local y son conocidos también como 'propios', 'mandamás', 'duros' y 'la pesada'. De origen humilde la mayoría de ellos, empiezan como simples guaqueros y van acumulando con el tiempo enormes fortunas que intervienen por fuera de la región. Su personalidad carismática induce a que sean reverenciados y temidos por sus subalternos, quienes les consultan sus problemas. Desempeñan múltiples funciones, pues actúan como jueces cuando castigan a los infractores y recompensan a sus más fieles servidores: son árbitros en las querellas familiares y empleadores que les consiguen trabajo en las minas a sus allegados y a todos aquellos que quieren colocar bajo su tutela. (p. 100)

Dichos jefes esmeralderos también desempeñaron un papel importante en la pacificación de la zona y en el control militar y estratégico de las minas de esmeraldas. Bajo esta lógica se destaca

8 La cercanía de la zona esmeraldera a la ciudad religiosa del país (Chiquinquirá) permitió la 'deidificación' de muchos jefes esmeralderos, quienes usaban el discurso del catolicismo para demostrar su cercanía a los guaqueros y sus familias (Ortíz Rozo, 2015).

9 Los jefes esmeralderos o patrones, en muchas ocasiones, eran quienes patrocinaban las ferias y fiestas de los municipios, de esta forma daban a conocer su carisma -y a la vez autoridad-en los escenarios culturales. 
la presencia de Efraín González ${ }^{10}$, famoso bandolero de la segunda mitad del siglo xx, quien llegó en el año de 1960 al occidente de Boyacá reclutado por órdenes de los líderes de la mina de Muzo (Steiner, 2005).

La presencia de González en el occidente de Boyacá sirvió como una estrategia para apaciguar la zona y legitimar el control territorial y económico de las minas de esmeraldas por parte de los patrones, quienes se habían organizado en bandos, dependiendo la zona o el municipio en el que se encontraban. ${ }^{11}$ El uso estratégico de la violencia y el miedo fueron las principales herramientas que usó González para establecerse, en poco tiempo, como el estratega militar y el "protector" de los esmeralderos (Steiner, 2005). La eficiencia de González en el occidente de Boyacá se ve enmarcada en las dinámicas políticas y sociales que maneja la zona, lo cual permitió que sus ideas políticas se acoplaran rápidamente a sus intereses y forma de trabajo. Un argumento de esta afirmación es el que nos brinda Steiner (2005), quien afirma:

El grupo social donde más se ajustaban los métodos y convicciones políticas de Efraín fue provisto por una característica particular de la región: las minas de esmeralda del occidente de Boyacá, zona que en la historia del país ha sido para el Estado más un dolor de cabeza que una fuente de beneficios. (p. 242)

10 González nació en 1933 en Jesús María (Santander), su madre fue asesinada por liberales tres años después de su nacimiento. A diferencia de muchos otros bandoleros, Efraín González destacó por ser un convencido de las ideas conservadoras; en 1958 desertó del ejército y más tarde se convertiría en un destacado guerrillero de la cuadrilla del bandolero Jair Giraldo -también conservador-. Efraín González emerge como bandolero en un escenario posterior al

Frente Nacional (Steiner, 2005).

11 Como una forma de ilustrar este ejemplo podemos destacar a la organización de esmeralderos denominada 'La Pesada', de la cual habla Gutiérrez y Barón (2008): “La principal organización de esmeralderos era "La Pesada", un grupo criminal en el que participaban varios líderes esmeralderos. La banda lidiaba con "amenazas internas" (ladrones, guaqueros independientes, etc.). La estabilidad de la zona esmeraldera de Boyacá puede explicarse por el hecho de que el único proveedor extraestatal de seguridad poderosa era la articulación de "La Pesada" con un "bandolero político" (p. 108). 
En 1965 fue asesinado, en Bogotá, Efraín González por miembros del ejército en una operación que necesitó más de 200 soldados (Steiner, 2005). Uno de los efectos más trascendentales de dicha muerte se dio en el occidente de Boyacá, ya que este bandolero se había constituido en un agente pacificador y regulador de las relaciones entre esmeralderos por el control de las minas. Resultado de ello fue el aumento de los asaltos y el desborde de la práctica del guaqueo, lo cual reflejó un panorama de desorden público (Gutiérrez y Barón, 2008). La realidad fue que el orden se perdió en la zona y el poder se atomizó en diversos líderes regionales, que posteriormente se disputarían, de manera violenta, muchos de los escenarios de explotación minera del occidente de Boyacá.

Posteriormente, se reemplazó el puesto de González con un primo que él tenía, Humberto Ariza, alias "El Ganso". Sobre el papel de Ariza en la zona, y su ineficiencia en la generación de un orden social similar al que había dejado su primo, Gutiérrez y Barón (2008) mencionan:

Los miembros de "La Pesada" tenían claro que se requería de alguien que ejerciera autoridad en la zona y restaurara el orden perdido. Llegaron a la conclusión de que la figura ideal para hacerlo era Humberto Ariza, alias "El Ganso", primo de Efraín González. Pero Ariza no logró consolidar su autoridad en la región y terminó yéndose en contra de sus jefes. (p. 110)

El papel de Ariza, en términos políticos y sociales, no fue bastante relevante en el momento, ya que no logró establecer una voz preponderante en la regulación de la vida social de los habitantes del municipio, como lo hizo en su momento su primo Efraín González. Por otro lado, las relaciones de los esmeralderos con el Estado no eran las mejores; en 1968, mediante el decreto 912 el gobierno de Carlos Lleras Restrepo creó Ecominas, empresa a la que posteriormente se le otorgarían las herramientas y facultades jurídicas para regular las concesiones de las minas de Coscuez, Peñas Blancas y 
las de Muzo (Gutiérrez y Barón, 2008), es decir, se monopolizó el acceso a la explotación de las minas por parte del Estado.

Ante este panorama, los líderes esmeralderos, en cabeza de Isauro Murcia, lograron establecer estrategias de infiltración en Ecominas, esto con el fin de generar un colapso al interior mediante una red de sobornos a funcionaros y el fomento de técnicas clandestinas de hallazgo de piedras, como el guaqueo (Gutiérrez y Barón, 2008). Los últimos dos años de la década de los sesenta y la primera mitad de los setenta son claves para entender la posterior ola de violencia que se aproximaba al occidente de Boyacá. Al interior de la zona esmeraldera las tareas esenciales del Estado no eran precisamente realizadas por aparatos burocráticos, como suele ser común en algunas zonas del centro del país; al igual que en muchos lugares periféricos de Colombia, donde existe una presencia diferenciada del Estado (González, 2016); fueron los actores armados no estatales (patrones y sus ejércitos privados) los encargados de generar un orden jurídico, prestar servicios de seguridad dentro de la sociedad, ser los encargados de administrar la justicia y, por último, promover el bienestar social en los habitantes de los municipios ubicados en el occidente de Boyacá (Ortíz Rozo, 2015).

Fue bajo esta lógica que concluyó la primera etapa de la violencia esmeraldera del occidente de Boyacá, ${ }^{12}$ un lapso en el que se configuró todo un sistema político alternativo bajo un compendio de instituciones informales basadas en la débil e ineficiente presencia del Estado y la hegemonía de diversos líderes regionales que controlaban los diferentes espacios económicos, sociales y políticos de la vida de los habitantes del occidente de Boyacá.

La Segunda Guerra Verde (1975-1978) se caracterizó por la explotación mixta de las minas de esmeralda, una explotación basada

12 Lo que bien se conoce como Primera Guerra Verde (1965-1971) 
en la cooperación de la empresa privada, junto con los jefes esmeralderos y su control "informal" sobre dichas minas. Sin embargo, esta estrategia no permitió entablar diálogos robustos y eficientes con aquellos jefes que no lograron establecerse en la legalidad o simplemente decidieron no hacerlo, ya que consideraban que las minas no deberían ser reguladas por el Estado.

Por otro lado, la estrategia de algunos patrones para infiltrarse en las empresas privadas a las cuales se les iba a adjudicar la extracción esmeraldera funcionó, ya que pocos años después lograrían legalizar sus fortunas y adquirir el estatus de empresarios legales (Gutiérrez y Barón, 2008). Sin embargo, este proceso permitió que los jefes se dividieran en dos, por un lado, quienes ya se encontraban ejerciendo actividades dentro de la minería legal, y, por el otro, quienes se negaban a compartir su facultad para la explotación o simplemente consideraban que no era rentable pasarse a la legalidad.

Esta diferenciación permitió que se comenzara a gestar una nueva ola de violencia, ya que el Estado no contó con que haber dejado de lado la presencia de algunos patrones podría conllevar a que se generaran nuevos conflictos. Bajo esta lógica, el período 1975 1978 se caracterizó por una presencia más intensa del Estado, pero poco eficiente; la privatización parcial de las minas de esmeraldas de Coscuéz, Muzo y Peñas Blancas, y la gestación de nuevas rivalidades entre jefes esmeralderos, quienes posteriormente se organizarían en "bandos familiares" para armarse, defenderse y luchar por el control de la explotación de las minas esmeralderas.

La Segunda Guerra Verde concluyó con la firma del pacto de paz entre esmeralderos en 1978, en el cual se asignaron a particulares la explotación de las tres minas principales del occidente de Boyacá (Coscuez, Peñas Blancas y Muzo). Sobre este pacto Gutiérrez y Barón (2008) mencionan: 
El acuerdo coincide con la licitación y adjudicación de las minas de esmeraldas a particulares para su explotación. Este pacto de paz generó dos efectos claros. Por un lado, la consolidación del monopolio sobre la explotación y comercialización de las esmeraldas por parte de los favorecidos con la adjudicación de las minas de Muzo (Isauro Murcia y luego Gilberto Molina) y Peñas Blancas y Coscuez ("Pacho" Vargas). Por otro lado, el fortalecimiento de un grupo de guaqueros instalados, desde la época de la primera guerra, en el área de "La Culebrera" en Coscuez y las minas de Peñas Blancas. (p. 111)

El pacto de paz no pudo contener las inminentes tensiones que había entre esmeralderos, lo cual conllevó a que, posteriormente, el occidente de Boyacá viviera su época más violenta de la historia: los años ochenta. Sumado a ello, la influencia del narcotráfico ${ }^{13}$ fue un factor determinante en las relaciones sociales y políticas de la región; sin embargo, los mismos jefes esmeralderos fueron precavidos en este tipo de alianzas y lograron desligarse de cualquier vínculo con el narcotráfico, a excepción de algunas alianzas con Gonzalo Rodríguez Gacha, pero que no representaron mayor trascendencia, a diferencia de otras regiones en el país, que se han visto terriblemente perjudicados por las secuelas del narcotráfico y que, al día de hoy, no logran reestablecer el tejido social destruido por la lógica violenta de la producción y distribución de cocaína.

La explotación mixta de esmeralda comenzaba a dar los primeros frutos para el Estado y para aquellos jefes esmeralderos que habían adquirido el estatus de empresarios, ya que en 1984 las exportaciones de esmeralda llegaron a los 30 millones de dólares y se mantuvo en constante subida hasta su punto máximo, en 1995, cuando se registraron ganancias por 452 millones de dólares (Gutiérrez y Barón, 2008). Sin embargo, este aumento de ganancias

13 Aunque allí el narcotráfico no se vivió con la misma intensidad que en otros territorios, sí se puede destacar la presencia de Gonzalo Rodríguez Gacha, alias "El Mexicano", quien logró establecer alianzas con el jefe esmeraldero Gilberto Molina. Por otro lado, el Occidente de Boyacá fue para El Mexicano un espacio territorial muy valioso, pues allí podía contar con amplias zonas de cultivo de hoja de coca y podía controlar con más facilidad las rutas de transporte cercanas al Magdalena Medio (Ortíz Rozo, 2015). 
exacerbó las tensiones de las familias que administraban las minas de Coscuez, quienes no se pusieron de acuerdo para establecer los turnos respectivos para la explotación de la mina. Dicho desacuerdo conllevó a que los jefes esmeralderos se dividieran en dos bandos: el bando de Borbur ${ }^{14}$ y el bando de Coscuez ${ }^{15}$ (o "los Culebreros"). Cada uno de ellos representaba el poder territorial y los intereses de las familias con más raigambre en los negocios de la explotación esmeraldera de las minas del occidente de Boyacá, por ende, esta guerra se constituyó como un escenario de conflictos familiares, donde el Estado no tuvo una intervención plausible y permitió que actores armados, ajenos a los márgenes de la legalidad, lograran desligarse de los esquemas del monopolio de la fuerza que supuestamente poseía el Estado. La consecuencia directa de estas acciones fue el aumento de las muertes y la violación de los derechos humanos, gracias a las acciones de unas élites (en este caso familias) que controlaban el monopolio de la fuerza (Ortíz Rozo, 2015).

Por un lado, el bando de Borbur buscaba la presencia del Estado y del ejército para hacer frente a la violencia que se vivía en la zona y, a su vez, como estrategia ofensiva ante los hostigamientos por parte del bando de Coscuez. Aunque el bando de Borbur buscó la presencia del ejército, nunca mermó sus acciones violentas en contra de la población. Por otro lado, el bando de Coscuez, por iniciativa de Gilberto Molina (empresario de esmeraldas y uno de los jefes del bando), entabló una alianza con Gonzalo Rodríguez Gacha, quien, posteriormente, se volvería enemigo a muerte de Molina ${ }^{16}$. Dicha

14 El bando de Borbur quedó integrado por familias de Santa Bárbara (vereda del municipio de San Pablo de Borbur), Borbur, Peñas Blancas, Muzo, Quípama y Otanche (Gutiérrez y Barón, 2008).

15 Integrado por las familias de Coscuez (vereda y mina de esmeraldas de San Pablo de Borbur), quienes posteriormente extenderían su dominio a los municipios de Pauna, Briceño, Coper y Buenavista (Gutiérrez y Barón, 2008).

16 Molina fue asesinado el 27 de febrero de 1989, en Sasaima, Cundinamarca. Murió junto con sus 16 guardaespaldas, pero no se sabe con exactitud si fue por la orden de Gonzalo Rodríguez Gacha o por las FARC, quienes estaban presentes en Muzo y tenían una enemistad con Molina. "El padrino de las esmeraldas" Revista Semana 04/03/1989, p. 1.; "Acribillados a balazos en Colombia el 'rey de las esmeraldas' y sus 16 guardaespaldas", Diario El País, España 27/02/1989. 
alianza permitió un debilitamiento de las relaciones entre este bando y el Estado, esto a causa de sus relaciones con el narcotráfico (Gutiérrez y Barón, 2008).

Esta guerra de familias jugó un papel muy importante en la posterior configuración de un acuerdo de paz en 1989, que sería bastante conciso y pétreo, en el sentido de que se ha cumplido con bastante cabalidad a causa del compromiso de los jefes esmeralderos en la búsqueda de la disminución de la violencia en la región. Dicho acuerdo se desarrolló bajo la iniciativa de los mismos jefes esmeralderos, quienes buscaron pacificar el territorio mediante diversas propuestas que permitieran la inclusión de esmeralderos informales en la extracción mixta de las gemas. Los principales puntos de dicho acuerdo, según Gutiérrez y Barón (2008), son los siguientes:

a. Cese inmediato del fuego.

b. Los dos bandos se comprometieron a desmantelar a sus grupos de gatilleros.

c. El Estado vigilaría el desarrollo del proceso, fortaleciendo la justicia y la lucha contra la impunidad.

d. Veeduría de la Iglesia ${ }^{17}$ y el ejército para garantizar el cumplimiento de los acuerdos.

e. Suspensión de cualquier actividad relacionada con el narcotráfico.

f. Ampliación de la participación en la explotación esmeraldífera. Este punto estaba dirigido básicamente a regular la explotación de la producción de Coscuez. Los socios de Esmerarcol S. A. -operadora legal de las minas de Coscuez-

17 La iglesia ha jugado un rol importante en las relaciones conflictivas del occidente de Boyacá, pues la cercanía a Chiquinquirá (ciudad religiosa de Colombia) y su configuración como espacio central de conectividad entre Bogotá y el resto del departamento, generó un alto grado de devoción por parte de los jefes, lo cual permitió que la iglesia adquiriera un grado de aceptación y autoridad bastante alto. 
cederían sus derechos legales de explotación, para permitir así la participación de otros sectores interesados en el filón. (Gutiérrez y Barón, 2008)

De esta forma fue como se desarrolló la Tercera -y últimaGuerra Verde (1986-1990), la cual dejó como resultado más de 400 muertos y quedó en la historia como la época más violenta de dicha región, tal como podemos evidenciar en el gráfico 1. Asimismo, este gráfico permite evidenciar la disminución de muertes en el occidente de Boyacá, después de 1989 y 1991, cuando se firma el pacto de paz y se establece el Consejo de Paz, respectivamente.

Gráfico 1.

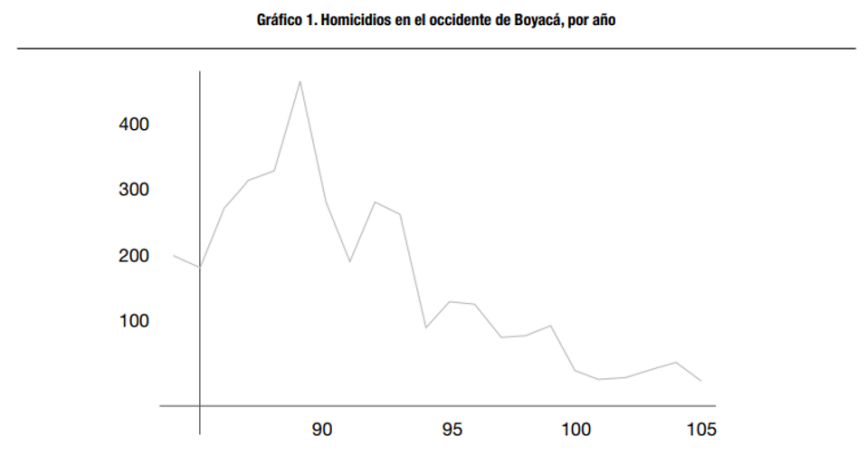

Municipios: Chiquinquirá, Briceño, Buenavista, Caldas, Coper, La Victoria, Maripí, Muzo, Otanche, Pauna, Quípama, Saboyá, San Miguel de Sema, San Pablo de Borbur, Tonungua.

Fuente: Policía del departmento de Boyacá.

Fuente: Gutiérrez \& Barón, 2008, p. 122.

\section{Caracterización de los actores y dinámicas dentro del período de guerra ocurrido entre 1986 y 1990}

Conociendo ya el origen y la configuración de los bandos Coscuez y Borbur, mencionados anteriormente, ahora se procederá a señalar la importancia de estos dos bandos en torno a la guerra que se gestó en el occidente de Boyacá, en el periodo comprendido entre 
1986 y 1990. Además, se mencionará cómo, alrededor de dichos bandos, se constituían las relaciones sociales en la zona, es decir, los actores y las dinámicas que tenían lugar en dicho periodo.

Respecto al primero de los bandos, Uribe Alarcón (1991) señala que "el grupo Coscuez se caracterizaba por aglutinar en su interior a guaqueros y comerciantes; quienes se encontraban involucrados en una disputa regional por el control de los territorios de explotación esmeraldífera". Asimismo, menciona que dicha lucha "contó con el apoyo del narcotraficante Gonzalo Rodríguez Gacha, quién tenía estrechas relaciones con las personas del bando Coscuez y por ello se dispuso a encerrar al bando contrario, al bando Borbur, en los territorios sometidos bajo su influencia” (Uribe Alarcón, 1991, p. 21). En lo que respecta al bando Borbur, este se encontraba aliado con el ejército, la iglesia y políticos del nivel nacional. Se evidencia entonces que cada uno de los bandos contaba con un respaldo particular para llevar a cabo sus actividades en la región; el bando Coscuez contaba con un respaldo de la organización endógena de la sociedad que allí habitaba, mientras que el bando Borbur se encontraba respaldado por las instituciones del orden estatal y religioso.

Ahora bien, es pertinente aclarar que dentro de las dinámicas predominantes en la "tercera guerra verde", resulta de gran importancia aquella que se refiere a la jerarquización de los actores de los bandos que la protagonizaron. Entonces, vale señalar que "en la base de la organización se encontraban los mineros llamados guaqueros, y los campesinos, que hacen las veces de guaqueros ocasionales (Uribe Alarcón, 1991, p. 22). Los guaqueros constituían el grupo social dentro de la explotación de esmeraldas, que recibía víveres y herramientas a cambio de su fuerza de trabajo en las minas.

Continuando con la descripción de la jerarquía existente en torno al conflicto de la región esmeraldífera, es pertinente señalar que el grupo que se encuentra un escalón arriba de los guaqueros es el 
de los esmeralderos, "quienes han logrado, construir fortunas, crear relaciones de compadrazgo y padrinaje" (Londoño Reyes, 2015, p. 55) con los duros o patrones de la región; estos personajes, son quienes "logran ascender y coordinar las operaciones comerciales del negocio de las esmeraldas, son también los que ayudan en la logística de seguridad” (Londoño Reyes, 2015, p. 55).

Dentro de dicha jerarquía, el escalafón más alto es el de los patrones, quienes surgieron como consecuencia de "la falta de un Estado fuerte, de unas instituciones dedicadas a atender las necesidades sociales, la falta de liderazgos políticos y una región con amplios recursos económicos" (Londoño Reyes, 2015, p. 59). De modo que, estos patrones hicieron posible la aparición de nuevos líderes en el occidente de Boyacá que, debido a su conocimiento de la zona, contribuyeron a encontrar nuevas minas o yacimientos para la explotación de esmeraldas y, procedieron a apropiarse de estas y a repartirlas entre sus familiares.

Por otro lado, es importante señalar que para el periodo comprendido entre 1986 y 1990, en la región esmeraldífera del occidente de Boyacá, existía una "masa flotante de guaqueros, procedentes de todas las regiones del país, compuesta por hombres, mujeres, niños, vagabundos, desocupados y aventureros dedicados a la minería clandestina y atrapados por el fantasma de la acumulación rápida” (Uribe Alarcón, 1991, p. 19). Lo cual hizo que la región se configurara en torno a una cultura de los acuerdos de palabra, tal como lo enuncia (Uribe Alarcón, 1991), diciendo que "en este escenario, caracterizado por la resolución violenta de los conflictos y por el afán de lucro, la cultura de los esmeralderos gira en torno a valores absolutos como Ia lealtad y la palabra” (Uribe Alarcón, 1991, p. 22).

Teniendo en cuenta lo anterior, podemos decir que aquello que se ha nombrado hasta ahora tiene una relación más estrecha con las dinámicas emanadas del bando Coscuez, como actor del periodo 
de violencia que se estudia. Pasaremos, ahora, a ahondar respecto a las dinámicas que rodeaban al otro actor fundamental de la tercera guerra verde, a saber, el bando Borbur que, como ya se mencionó anteriormente, tuvo vínculos con el ejército, la iglesia y políticos a nivel nacional.

Sin embargo, antes de empezar a hablar de los vínculos del bando Borbur, hay que señalar la importancia del aislamiento de las dinámicas al interior del occidente de Boyacá, del resto del país. Pues, con la llegada de los años 80 se cumplía una década desde que el Estado colombiano le cedió las minas esmeraldíferas a concesionarios particulares, y para entonces, el Estado le había adjudicado las minas de Quipama y Muzo a la empresa TECMINAS. Uno de los principales socios de la empresa en la zona era Gilberto Molina, patrón esmeraldero y líder del bando Coscuez, quien por un tiempo estuvo aliado con Gonzalo Rodríguez Gacha. Sin la intervención directa del Estado en el negocio de las esmeraldas en la zona, la lógica del manejo y del progreso que se podía evidenciar allí recaía fundamentalmente en los líderes de ambos bandos, y en la jerarquía social establecida a partir de estos.

Ahora bien, el bando Borbur representaba, de algún modo, la institucionalidad, puesto que, según (Uribe Alarcón, 1991), "había surgido luego del asesinato, por parte del grupo Coscuéz, del concejal del municipio de Otanche, Laureano López". De modo que su creación puede ser interpretada como un llamado a la defensa de los representantes de las instituciones estatales a nivel local, y en contravía de las mafias gestadas en torno a las alianzas entre el mercado esmeraldero y los líderes del grupo Coscuez.

Además, el bando Borbur representaba también a la institucionalidad, en la medida en que, debido a sus vínculos con la iglesia y el ejército, ejercía un control tanto físico como cultural respecto al territorio. Pues, en la lógica de las personas jerárquicamente afiliadas 
a este grupo, se manejaba una "ética muy particular que consistía en cubrir los asesinatos con actos de caridad como repartir dinero a los más necesitados o de servicio público como construir escuelas u hospitales" (Uribe Alarcón, 1991, p. 22). Y esa ética se encontraba estrechamente relacionada con la moral religiosa que profesaban, a saber, la moral católica, porque, según (Uribe Alarcón, 1991), a los involucrados en la tercera guerra verde "los alentaba la creencia en una justicia divina que a la hora del juicio aplicará la ley de compensación”.

La tercera guerra verde en el occidente de Boyacá fue, entonces, un suceso que se salió del control de los bandos que la propiciaron, pues dejó cientos de personas muertas y un amplio número de víctimas en el periodo (1986-1990.) Por tal motivo, fue necesario llevar a cabo un proceso de paz para ponerle fin al conflicto en la región; ya que fue un conflicto marcado por los antecedentes de la primera y la segunda guerra verde.

\section{El proceso y acuerdo de paz en el occidente de Boyacá de 1986-1991 y las vicisitudes de su aparente éxito}

El proceso de paz en el occidente de Boyacá, denominado la paz verde $e^{18}$, se ha mostrado como un proceso con niveles exitosos, dado que se ha evidenciado una aparente disminución del conflicto violento entre los principales grupos o bandas ya caracterizados, así "lo municipios como Muzo, Otanche, Coscuez, entre otros se convirtieron desde 1991 en referentes de orden en el contexto de la violencia que afectaba al país producto de la expansión de los actores armados irregulares"(Ortiz Rozo, 2015).

18 Término principalmente usado por Flórez Varela (2019) que responde a uno de los conflictos más violentos que han azotado la región, denominado Guerra Verde 0 Guerra por las esmeraldas. 
En términos generales, no hay claridad de cómo este proceso de paz comienza a gestarse; más bien se constituyó a partir de distintos actores e iniciativas que fueron encaminando el proceso. Uno de los actores sustanciales para este acuerdo de paz fue Víctor Carranza, el zar de las esmeraldas ${ }^{19}$, quién consolido un grupo con el objetivo de abonar el inicio del proceso de negociación, compuesto por personas del sector esmeraldero a quienes les rendía su confianza "para distribuir cartas a los desertores de los municipios del bando contrario, invitándolos a buscar alternativas para acabar con el conflicto"(Flórez Varela, 2019).

En este sentido, la autora menciona que:

Preocupados por la situación de violencia, en 1987 algunos sacerdotes de la región contactaron a diversos líderes de cada grupo para consolidar una iniciativa de paz, estableciendo encuentros clandestinos, los cuales representaba un gran peligro, dadas las condiciones de la guerra. Dicho trabajo se consolidó en la fase exploratoria de los acuerdos, pues a través de los diferentes comunicados y reuniones, se evaluaron las condiciones existentes para iniciar un proceso de diálogo y negociación en la región, que involucrara a todos los actores en conflicto. (Flórez Varela, 2019, p. 32)

Los alcaldes municipales: William Nandar (Alcalde de Muzo), Gabriel Parra (alcalde de Otanche) y Eccehomo Lara (alcalde de Maripí) estuvieron también inmersos en la iniciativa de las negociaciones, dándole vocería a la Iglesia católica, principalmente a través del Obispo de Chiquinquirá, Álvaro Raúl Jarro, para dar apoyo a los diálogos entre los esmeralderos.

19 Víctor Carranza nació en Guateque, Boyacá, el 8 de octubre de 1935. "Desde 1960, cuando encontró su primera mina, Peñas Blancas, su ascenso en ese mundo fue meteórico. Vendió piedras en Europa. Se asoció con otros. Consiguió permisos de explotación oficiales para él y sus amigos. [...] Carranza es el personaje más emblemático de ese medio siglo turbulento. No solo fue protagonista de primera línea en todas las guerras que ha vivido el país, no solo sobrevivió a casi todos sus enemigos, sino que terminó su vida en la más completa impunidad. Sobrevivió a los 'pájaros' de Ios años cincuenta, a las sangrientas guerras esmeralderas de los años sesenta a los ochenta, al Mexicano y a Pablo Escobar; a los hermanos Castaño y el paramilitarismo, a los ejércitos de Tirofijo que amenazaron sus fincas y hasta a las bandas criminales sucesoras de las AUC." Tomado de: https://www.semana.com/nacion/articulo/victor-carranza-intocable/338973-3/ 
Los intereses económicos inmersos fueron un aspecto crucial que impulsaba también las intenciones de generar un acuerdo de paz. Esto no solo se gestaba sobre el supuesto de la confrontación que traía consigo "un detrimento de la explotación y comercialización de las esmeraldas, producto de la campaña de desprestigio y estigmatización hacia los comerciantes de esta piedra y de la disminución de mano de obra"(Flórez Varela, 2019, p. 33), sino también una creciente presión internacional por buscar injerencia de control sobre las zonas esmeralderas con la progresiva apertura económica que se previsualizaba en la década de los ochenta, con el argumento que se cimentaba en que dichos bienes mineros son bienes del Estado y que la entrada de las empresas multinacionales sí generarían pagos de impuestos y regalías que los grandes propietarios de estas minas no proporcionaban; un punto central al cual apuntaba Charles Burgess ${ }^{20}$.

Charles Burgess conocería al Obispo de Chiquinquirá en 1987, quien le permitió conocer el entorno en el que la esmeralda era el centro del negocio, a la par, como menciona Burgess "Por medio de él, comencé a conocer a varias personas en este medio, él comenzó a pedirme favores de manera personal para ayudas"(Burgess, 2015). Lo que lo constituiría años más tarde, con la ayuda de Carranza, a dar entrada de empresas extranjeras para consolidar un proyecto de minería con empresarios de Houston.

La continua disputa que ha tenido el negocio de las esmeraldas hizo, entonces, que la amenaza por el control de las minas se sintiera en todos lados, por lo que para los grandes patronos esmeralderos, las primeras visualizaciones de la entrada de empresas de capital ex-

20 Presidente de Minerías Texas Colombia. Burgess llegó a Colombia a mediados de los años ochenta como funcionario de la embajada de Estados Unidos. En 1987 se casó con una colombiana. Por lo que conoció al obispo de Chiquinquirá, quien comenzó a darle a conocer un importante número de personas en el medio esmeraldero. Conocería a Carranza en 2006, cosa que ayudó a que se concretara, posteriormente, la idea que se venía gestando años atrás, la conformación del proyecto en 2009 con el apoyo de empresarios de Houston, que comenzaron operando en la mina de Muzo. 
tranjero generó un punto amenazante, en tanto propiciaba también la estigmatización generalizada de los comerciantes de la piedra por sus prácticas tradicionales, lo que años después, con la entrada ya constituida de estas empresas, se haría manifiesta la molestia por las nuevas empresas, afirmando que se estaban apoderando de recursos que pertenecían a la región(Baquero, 2017).

La entrada de guerrillas, en especial de las FARC, que operaban en los municipios de Pauna, Maripi, Briceño, Buenavista, Tununguá y La Victoria (Páramo Bonilla, 2011), junto con la disputa del control y poder territorial de las zonas mineras de los patrones esmeralderos, hizo que la presencia de autodefensas fuera justificada para regular las zonas y ejercer control. Con esto es evidente que la violencia sí ha sido un elemento determinante de la historia de la región, ha sido sistemática y cuenta con hitos violentos ${ }^{21}$ que se encarnan desde la colonia y constituyen un pasado que hace mella en la construcción social de estas zonas (Páramo Bonilla, 2011, p. 5)

La degradación de la guerra, los asesinatos y el miedo en la población conllevaron a que el inicio de las negociaciones fuese apoyado. En palabras de Flórez Varela (2019) (Citando a Gonzales, 2014), el alto grado de legitimidad que mantenían los esmeralderos en la población permitió que se iniciaran los primeros acercamientos a principios de 1990, y se organizó un encuentro en la base del Ejército, cerca de la quebrada Mioca, lugar donde se situaba la línea imaginaria que dividía a los dos bandos, contando con la participación de seis delegados de cada bando, el Ejército, la Policía y el Obispo de Chiquinquirá.(Florez Varela, 2019)

21 Páramo Bonilla hace una revisión etnohistórica del conflicto en el occidente de Boyacá que constituye una sucesión esquemática de hitos de violencia, la cual se asocia con múltiples formas de violencia. "Esta asociación no es gratuita, en todo caso, ya que se desprende de una demostrable historia de sucesivos episodios bélicos; una que inicia con las bandas de indígenas muzo y colima que prestaron una fiera resistencia a las huestes españolas durante la Conquista. y llega hasta nuestros días con la conformación de grupos privados de ofensiva militar."(Páramo Bonilla, 2011). Ver más en: (Páramo, 2011) El corrido del minero: hombres y guacas en el occidente de Boyacá. 
Se contemplan, entonces, los siguientes objetivos específicos ${ }^{22}$ por los cuales se realiza el acuerdo de paz:

1. Cese inmediato de toda agresión física o moral entre todos los habitantes de la región, en y fuera de ella.

2. Garantizar por parte de los habitantes de la comarca la libertad de tránsito de hombres, mujeres y niños, por todos los sectores de la región, con el compromiso, además, de concientizar sobre el tema de todos los habitantes en coordinación con las fuerzas armadas.

2.1 Garantizar la libre circulación de mercancías, actividades agropecuarias y mineras para las labores en toda la región.

3. Propender por la apertura bancaria y de sucursales de la Caja Agraria en los municipios de Muzo y Quípama y en otros del Banco de Occidente, donde la actividad económica lo permita. Para este proyecto quedan comisionados los señores alcaldes.

4. Facilitar el regreso progresivo de las gentes que por diferentes motivos tuvieron que abandonar sus propiedades.

5. Procurar el desarrollo regional, integrando los recursos municipales, regalías mineras, fondos de las empresas concesionarias de la explotación de la esmeralda. Para esto se buscará la manera de crear una fundación encargada de la organización y distribución de las posibilidades y de las buenas relaciones entre las empresas y los habitantes de la región.

6. Respaldar la acción de los concejos municipales de rehabilitación, para la consecución de recursos por parte del Gobierno Nacional, empresas y administraciones privadas.

22 Para ampliar la información respecto al objetivo general y específicos ver: Florez Varela (2019). LA PAZ VERDE. Escenarios de transformación de conflictos en el occidente de Boyacá. Universidad Nacional. (Anexo D) 
7. Procurar revitalizar y reorganizar a nivel municipal las asociaciones de municipalidades de la Cuenca del Río Minero, como instrumento regional de hermandad y desarrollo local.

8. Realizar las reuniones que se juzguen convenientes y útiles para formalizar este proceso de paz.

8.1 Para la reunión final solicitar respetuosamente la presencia del Ministerio de Gobierno, Ministerio de Justicia, Ministerio de Defensa, Procuraduría General de la Nación, Gobernación del Departamento, Dirección Nacional de Instrucción Criminal y el Tribunal Especial de Orden Público. Informar debidamente a los medios de comunicación social.

9. Apoyar todas las diligencias que pertenezcan a la Justicia Ordinaria y las labores propias de Instrucción Criminal, a fin de que se acabe la impunidad.

10. Procurar con el Gobierno Nacional, un proceso gradual de desarme en la región, con las excepciones que considere el Ministerio de Defensa Nacional para las empresas mineras, que cuenta con la concesión estatal.

10.1 Solicitar respetuosamente la derogatoria del Decreto n. ${ }^{\circ} 3037$ de 1986 al Gobierno Nacional.

11. Comprometernos en una plegaria por la paz así:

11.1 Misiones evangelizadoras por parte del Clero en la región. En las parroquias y sitios principales celebrar misas por la paz.

Sin embargo, se debe tener en claro que "Colombia convive un sistema político democrático con regímenes autoritarios en los órdenes locales”(Ortiz Rozo, 2015) y el occidente de Boyacá no está exento de estar inmerso en estas lógicas. Tal como lo analiza Ortiz Rozo (2015), existe un funcionamiento que coopta 
la institucionalidad y el espacio democrático, en tanto se presenta una dualidad entre tradición democrática nacional y órdenes locales autoritarios que se sustenta en las configuraciones locales provistas por el conflicto armado, enfocadas en la consolidación autoritaria del poder local. Estos órdenes locales se arraigan al territorio dadas las lógicas históricas de conformación del espacio, en los cuales los actores autoritarios son quienes proveen el sentimiento de cercanía de un tipo de Estado a las poblaciones locales, lejanas del nivel central.

En este sentido, el proceso de paz concretamente no mantuvo una implementación bajo un modelo democrático de participación en la que la población pudiera llevar una incidencia activa en este, sino que se desarrolló a través de organizaciones que actuaron como agentes activos de la violencia (Ortiz Rozo, 2015). Así entonces, el mantenimiento de la paz se ha dado dentro de la dinámica del autoritarismo subnacional ${ }^{23}$, en tanto ha sido sostenida a través de instituciones paralelas o informales que han hecho las veces de Estado para generar un marco de convivencia en los términos del autoritarismo que ordena la vida social en la zona.

Los acuerdos fueron el desarrollo de estrategias de los diferentes esmeralderos para mantener márgenes de cierta normalidad, sin acudir a autoridades públicas formales, sino más bien, generando un propio orden social que se entiende desde una presencia diferenciada del Estado (González, 2014), dado que este último no entra a generar espacios de convivencia, sino que se crean dentro de las propias

23 Eduard Gibson contribuye con la propuesta teórica de los autoritarismos subnacionales en tanto provee un marco de análisis de la configuración estratégica de la política del orden local, en la cual las elites autoritarias nacionales y locales llevan a cabo el control territorial de manera diferenciada. Asimismo, menciona Gibson: "El autoritarismo subnacional no debe ser entendido como un asunto local, sino como un resultado de dinámicas más amplias de gobernanza territorial nacional en regímenes democráticos. Los conflictos entre los autoritarismos y la oposición ocurren a través de múltiples ámbitos territoriales dentro del sistema político nacional" (Gibson, 2006). Así se demuestra una consolidación del modelo democrático a través de regímenes subnacionales que interactúan en el contexto nacional de manera alterna sobre los ejes de poder político, económico y social sobre el territorio. 
lógicas territoriales. En este sentido, la explotación de las minas de esmeralda y todo el entramado económico y social que gira en torno al negocio generan que la percepción de la población local sobre la autoridad, el orden y el Estado se entienda desde las dinámicas territoriales del conflicto y de los patronos esmeralderos, siendo quienes desarrollan las interacciones más cercanas de la vida social y económica, que el nivel central de poder no alcanza a gestionar enteramente en el territorio.

En 1991 se creó el consejo de paz para la región, y en su conjunto el Comité Permanente de normalización, verificación, pacificación y desarrollo del occidente de Boyacá, con la presencia de esmeralderos, el gobernador de Boyacá, el arzobispo de Chiquinquirá, el comandante de policía del departamento y el gerente de la compañía Mineralco (Ocampo et al., 1993), concretando así una presencia y control más fuerte de actores cívico-militares en la región.

Los impactos a la población tras este acuerdo, a pesar de que se establece una especie de pacto como estrategia de normalización, permea diferentes aspectos como: no haber participado activamente a la construcción de un orden social con miras en elementos realmente democráticos; la lejanía de tener garantías de derechos para las víctimas del conflicto, las cuales terminan por no ser visibilizadas; la salida de la ciudadanía en la injerencia de derechos económicos que solo se disputan entre élites locales, regionales, nacionales y demás actores en torno al negocio de la esmeralda. Se presentó, entonces, una "la debilidad de los mecanismos administrativos y judiciales para garantizar verdad y justicia [...] sin que se desarrollaran procesos evolutivos que permitieran la democratización efectiva de las diferentes instituciones del nivel subnacional" (Ortiz Rozo, 2015, p. 15), haciendo que el acuerdo de paz termine por generar una normatividad dentro de los márgenes de obediencia y lealtad, en promesa de terminar el conflicto violento. 
En términos generales, el éxito del proceso se paz se debió principalmente al manejo de un pacto entre patronos esmeralderos y organizaciones influyentes como estrategia para mantener en salvaguarda el negocio en la región, a mano de "autoritarismos subnacionales", que cooptaron los espacios democráticos e hicieron las veces de Estado para mantener una aparente convivencia, sin posibilidad de participación popular. A pesar de esta falta de control y participación popular, la promesa de por fin dejar el conflicto armado directo en el territorio fue el eje central sobre el cual versó la confianza de la población en el occidente de Boyacá para permitir que el proceso de paz se llevara a cabo de la manera en la que se desarrolló.

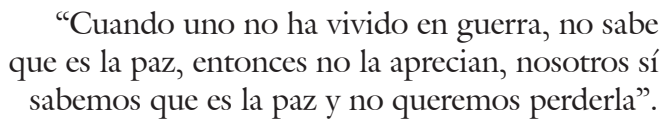

José Campos ${ }^{24}$

\section{Conclusiones:}

Los periodos de violencia vividos en el occidente de Boyacá, previos a la llegada de la década de 1980, dan cuenta de la filtración de la violencia en el periodo que va desde 1986 hasta 1990; pues muestran cómo se estableció una jerarquía social en la zona que repercutió en el manejo de la explotación de esmeraldas y en la disputa territorial por el control de la zona entre dos bandos.

Se muestra también la influencia de los factores socioeconómicos y socioculturales en el establecimiento de la jerarquía social y las dinámicas de violencia en la zona, pues los denominados guaqueros son personas provenientes de un bajo origen social y económico que

24 Fragmento de entrevista tomada de Flórez Varela (2019) a José Campos (entrevista, 18 de octubre de 2019): "el Acuerdo regional contó con tres ejes fundamentales: Paz, Perdón y Olvido. La Paz representada con la firma de los acuerdos, el perdón ante los vejámenes acaecidos en la guerra por los grupos en confrontación y el olvido reflejado en la indiferencia e indolencia del Estado ante las grandes problemáticas y necesidades de la región"(Flórez Varela, 2019). 
muchas veces son migrantes de otras zonas del país y se ven atraídos por la ilusión de acumular dinero rápidamente a través del negocio de las esmeraldas.

Por otro lado, el factor religioso es determinante también en las dinámicas de la región, particularmente el catolicismo, ya que a través de él se legitiman acciones de violencia en contra del adversario. Además, se evidencia que la jerarquía posiblemente originada en los trasegares de las distintas épocas de violencia que ha atravesado la región, persisten todavía, en tiempos recientes, en el ordenamiento político y social de la zona, dicha jerarquía está compuesta, a saber, de guaqueros (en la base), esmeralderos (en la mitad) y de patrones (en la cima del escalafón).

También es preciso afirmar que en el caso del occidente de Boyacá se evidencia una fuerte presencia de actores subalternos al Estado, los cuales terminan configurando las relaciones sociales y políticas del municipio. Es por ello por lo que la búsqueda de paz no ha sido una iniciativa del Estado, sino que ha sido una idea por parte de jefes esmeralderos para regular la extracción de esmeraldas y evitar un colapso en los precios de las gemas. Asimismo, la iglesia católica ha sido determinante en dichos procesos, pues su legitimidad -generada desde aspectos históricos y culturales- dentro de los grupos esmeralderos ha permitido que se vuelva una forma de llenar algunos significantes vacíos que el mismo Estado no ha podido llenar.

\section{Referencias}

Baquero, P. (2017). La nueva guerra verde. Planeta.

Burgess, C. (2015). Minería Texas: Marcando la Diferencia. Entrevista Con Charles Burgess. País Minero News. https://www.paisminero.com/index.php?option=com_ tags\&view $=$ tag\&id = 426: mineria-texas-colombia 
Florez Varela, Á. M. (2019). La Paz Verde. Escenarios de transformación de conflictos en el occidente de Boyacá. Universidad Nacional.

Gibson, E. ((enero-junio) de 2006). Autoritarismo subnacional: estrategias territoriales de control político en regímenes democráticos. Desafíos, 14 . https://revistas.urosario. edu.co/index.php/desafios/article/view/741

González, F. (2016). ¿Colapso parcial o presencia diferenciada del Estado en colombia?: una mirada desde la historiA. En A. varios, Colombia, lecturas de contexto (pp. 6-40). Bogotá: Conflict prevention and peace forum .

González, F. (2014). Poder y Violencia. CINEP-ODECOFI.

Gutiérrez, F. y Barón, M. (2008). Órdenes subsidiarios. Coca, esmeraldas: la guerra y la paz. Colombia Internacional, 67, 102-129.

Londoño Reyes, J. C. (2015). Narrativas en torno a la relación minería y violencia en la región del occidente de Boyacá. 122: Repositorio Universidad Distrital Francisco José de Caldas.

Ocampo, M., Rangel, C. y Sánchez, T. (1993). Oficina de Orden Público y Convivencia Ciudadana. Bogotá: Ministerio de Gobierno.

Ortíz Rozo, D. F. (2015). Los Acuerdos de Paz en el occidente de Boyacá (1986-1991): Un análisis de la convivencia pacífica a la luz de los autorismos subnacionales (tesis de pregrado). Bogotá: Universidad Colegio Mayor de Nuestra Señora del Rosario .

Palacios, M. (1995). Entre la legitimidad y la violencia: Colombia 1875-1994. Bogotá: Grupo Editorial Norma.

Palacios, M. y Safford, F. (2012). Historia de Colombia. País fragmentado, sociedad dividida. Bogotá: Universidad de los Andes - Facultad de Administración.

Páramo Bonilla, C. G. (2011). El corrido del minero: hombres y guacas en el occidente de Boyacá. Maguaré, 25(1), 25-109.

Steiner, C. (2005). Un bandolero para el recuerdo: Efraín González, también conocido como "el siete colores". Antípoda, (2), 229-252.

Uribe Alarcón, M. (1991). La guerra y la paz privadas: El occidente de Boyacá. Análisis 5: Conflicto social y violencia en Colombia. Documentos ocasionales No.64. Número Extraordinario, 19-23.

Uribe, M. V. (1992). Limpiar la tierra. Guerra y poder entre esmeralderos. Bogotá: CINEP. 